\title{
The stem group teleost Pachycormus (Pachycormiformes: Pachycormidae) from the Upper Lias (Lower Jurassic) of Strawberry Bank, UK
}

\author{
John J. Cawley ${ }^{1,2} \cdot$ Jürgen Kriwet ${ }^{1} \cdot$ Stefanie Klug ${ }^{2,3} \cdot$ Michael J. Benton $^{2}$
}

Received: 13 October 2017 / Accepted: 8 July 2018 / Published online: 20 September 2018

(c) The Author(s) 2018

\begin{abstract}
Three-dimensionally preserved specimens of the pachycormiform neopterygian Pachycormus from the Lower Jurassic (Upper Lias) of Strawberry Bank, Ilminster, UK, are described for the first time, and we present new and detailed morphological descriptions of the skull, trunk and fins of these specimens. The cranial material is characteristic of Pachycormus macropterus, with its operculum being twice as long as it is deep and the ventral angle lying towards the posterior half of the bone, and the preorbital portion occupying up to one-third of the skull. The description of the caudal fin conflicts with previous descriptions of caudal fins assumed to belong to Pachycormus. This raises the question of whether the other caudal fins belong to different species of Pachycormus, or whether it could be a case of intraspecific variability and is in conflict with morphometric data suggesting a monospecific status for Pachycormus. Recent phylogenetic analysis indicates that Pachycormus is sister taxon to Ohmdenia, which is an intermediate form between Pachycormus and the later giant suspension-feeding pachycormids. An alternative phylogenetic analysis reveals Pachycormus to be among the most basal pachycormiforms due to its incorporation of characters present in both hyper-carnivorous and suspension-feeding clades. We suggest future research on these specimens such as CT scanning of the skull may offer vital data regarding pachycormiform morphology and actinopterygian evolution, particularly the sister group relationship of pachycormiforms to the successful teleost fishes. In the future it may be important to focus on caudal fin characters of articulated specimens to identify possible cryptic species diversities within Pachycormus and also other members of Pachycormiformes.
\end{abstract}

Keywords Actinopterygii $\cdot$ Toarcian $\cdot 3 \mathrm{D}$ preservation $\cdot$ Caudal fin $\cdot$ Strawberry Bank $\cdot$ Description

Handling editor: Adriana López-Arbarello.

Electronic supplementary material The online version of this article (https://doi.org/10.1007/s12542-018-0431-7) contains supplementary material, which is available to authorized users.

John J. Cawley

john.cawley@univie.ac.at

1 Department of Paleontology, University of Vienna, Geozentrum, Althanstrasse 14, Vienna, Austria

2 Department of Earth Sciences, University of Bristol, Wills Memorial Building, Queen's Road, Bristol BS8 1RJ, UK

3 School of Science (GAUSS), Georg-August University, Justus-von-Liebig-Weg 11, 37077 Göttingen, Germany

\section{Introduction}

Pachycormiformes was a successful order of stem-group teleost fishes (Arratia 2004, 2013; Arratia and Lambers 1996) that thrived in the oceans of the Mesozoic for over $100 \mathrm{myr}$ (Friedman et al. 2010). They are an order comprising only a single family, Pachycormidae, of 17 genera that display great disparities in morphology, from streamlined open ocean tunalike predators to large suspension-feeding fishes with blunt rostra, and billfish-like forms with large pointed rostra and serrated pectoral fins (Lambers 1992; Friedman et al. 2010). Members of Pachycormiformes are easily identified by a combination of characters that include a compound rostrodermethmoid bone, extremely elongated pectoral fins, reduced or absent pelvic fin, a deeply forked caudal fin, rhombic scales that are either reduced in size or lost altogether, and other characters noted by Mainwaring (1978). One character Mainwaring used for Pachycormiformes, the scythe-like shape of the 
pectoral fin, is no longer a synapomorphy due to an analysis by Maltese and Liston (2014) that looked at pectoral fin morphology in pachycormiforms and found the pectoral fins to be more diverse in shape than previously realized. However, most pachycormiform specimens described so far are poorly preserved and mostly fragmentary (Woodward 1890, 1896; Hudson and Martill 1994; Delsate 1999; Everhart 2005; Kear 2007; Friedman 2012; Gouiric-Cavalli and Cione 2015), rendering the identification of unambiguous characters occasionally difficult, though taxa like Orthocormus can contain exceptionally preserved and thus taxonomically informative specimens (Lambers 1988; Arratia and Schultze 2013).

Here we describe new specimens of Pachycormus in exceptional three-dimensional preservation from the Upper Lias (Toarcian) of Strawberry Bank at Ilminster, Somerset, UK (Fig. 1) (see Pierce and Benton 2006; Williams et al. 2015 for additional information about the geological setting of Strawberry Bank). The marine limestones of the Strawberry Bank site are dated as Lower Jurassic (lower Toarcian, Upper Lias, 183 myr; Williams et al. 2015). Fossils occur in nodules and comprise arthropods, plants and exceptional three-dimensionally preserved fishes and reptiles (Moore 1864; Hallam 1967). The site was discovered by Charles Moore in the late 1840s, and by 1861 the site was filled so that no more fossils could be extracted. However, prior to the closure of the quarry, Charles Moore assembled a remarkable collection that was sold on his death to the Bath Royal Literary and Scientific Institution (BRLSI), and has remained there ever since. It has only recently attracted attention, with the first descriptions of remarkable threedimensional fossils of a small marine crocodilian Pelagosaurus typus (Pierce and Benton 2006) and ichthyosaurs (Caine and Benton 2011; Marek et al. 2015). Like these reptilian studies, this project is part of the Jurassic Ecosystem of Strawberry Bank Ilminster (JESBI) initiative, a collaboration between the BRLSI and the Palaeobiology and Biodiversity Research Group at the University of Bristol to work on the Charles Moore collection (Williams et al. 2015).

The intention of the study herein is to present a morphological re-description of Pachycormus macropterus based on three-dimensionally preserved specimens (Fig. 2) that allows an accurate evaluation of characters. The new information enables us to discuss its systematic affinities. A new phylogenetic analysis of Pachycormus, however, is beyond the scope of this paper.

\section{Materials and methods}

\section{Specimens}

Among the BRLSI collection, we identified 98 threedimensionally preserved specimens of Pachycormus (see
Supplementary Material) with total lengths ranging from 23.5 to $85 \mathrm{~cm}$ (BRLSI M1337 and BRLSI M1308, respectively). Most parts of the morphology have been preserved in exquisite detail. For the study, we selected those specimens that showed the best and most complete details of the skull, pectoral girdle, and pectoral and caudal fins, and are the basis for the description presented here. Further details were added to the descriptions and illustrations by a careful survey of the remainder of the collection.

\section{Preparation, photography and illustration}

All the BRLSI specimens were prepared to a greater or lesser extent in Victorian times, presumably by Charles Moore himself. The earlier work was satisfactory for its time, but he used heavy chisels, and the bone surface has often been damaged. For the present study, certain specimens were selected for further preparation at Bristol Museum and Art Gallery by skilled fossil preparator Lorie Barber. Remaining matrix was removed from the bone surfaces using a Model TT Fossil Preparation Pen pneumatic drill. Another pneumatic tool, a Micro Jack 2, was used to remove the thin veneer of matrix covering the surfaces. For fine-detailed preparation, a pin vise with a sharpened carbide rod was used. A consolidant, Paraloid B-72 diluted in ethanol, was applied to all bone surfaces. Sometimes more than one coat was applied, depending on the fragility of the bone. Cyanoacrylate (Tufloc no. 6) was applied to tiny cracks and areas of perceived weakness using a pair of tweezers. Tiny fragments that occasionally broke were glued back onto the surface using cyanoacrylate. On some of the specimens, Apoxie Sculpt epoxy putty was used to fill gaps and cracks.

After preparation, specimens were photographed using a Nikon D40 camera with a $60 \mathrm{~mm}$ Micro Nikkor lens stabilized by a wall-mounted camera stand. Drawings were made using a combination of camera lucida, Adobe Photoshop CS3 and Adobe Illustrator CS3.

\section{Morphological terminology}

The nomenclature used for dermal skull bones in actinopterygians has often followed a traditional ("orthodox") terminology that is not based on homology criteria. Difficulties in establishing homology, and the sometimes great variability of dermal elements in the head of actinopterygian fishes (e.g., Gregory 1933), led to the use of different names for the same bone (see also Schultze and Arsenault 1985). The terminology for the dermal skull used in this study follows that of Westoll (1943), Jollie (1962) and Schultze (1993, 2008), who established homology criteria for skull bones in fishes. 


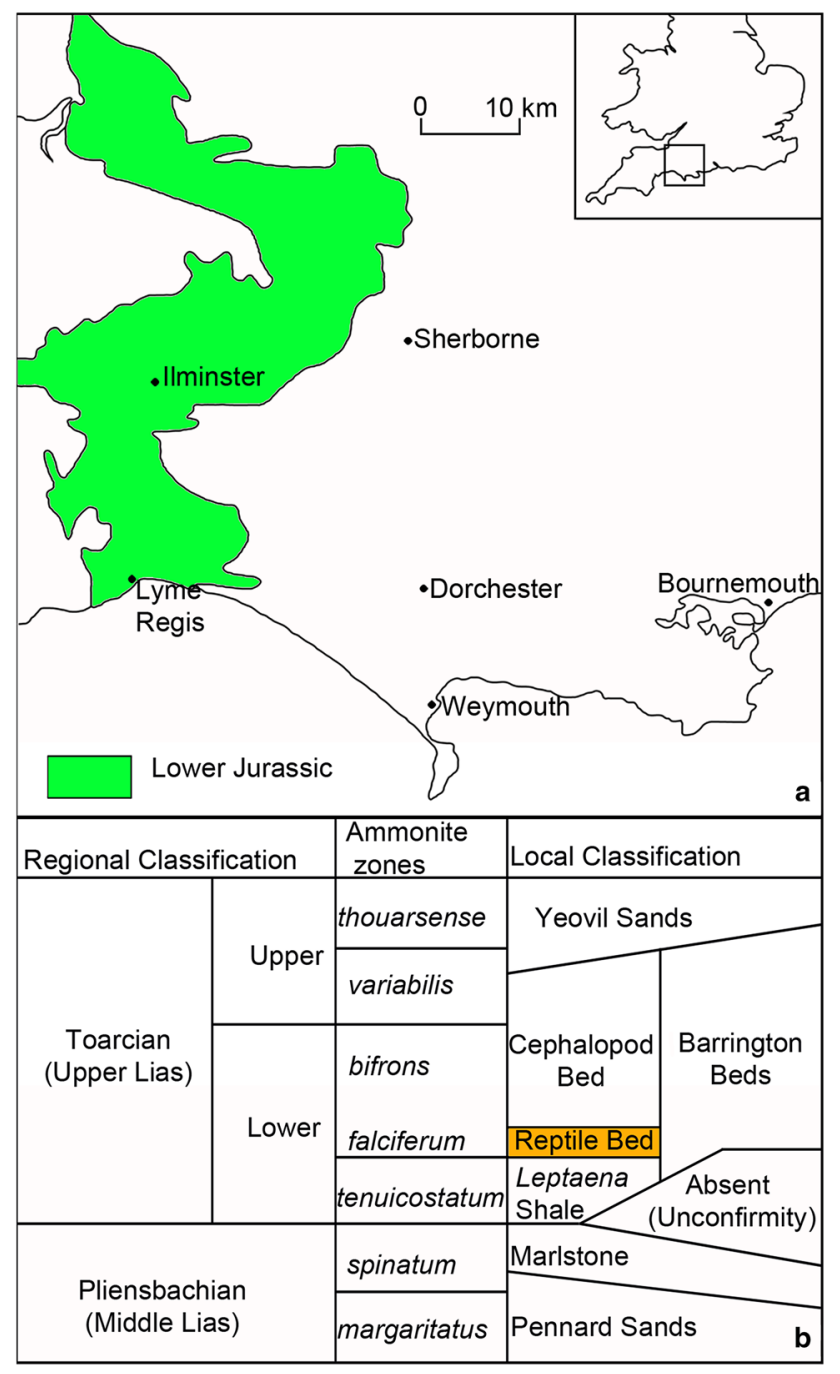

Fig. 1 Location and stratigraphy of the Strawberry Bank quarry where the Pachycormus specimens were discovered. a Location map; b stratigraphy of the Middle and Upper Lias deposits Modified from Williams et al. (2015). Redrafted with the permission of the Society of Vertebrate Paleontology

\section{Institutional abbreviations}

BRLSI-Bath Royal Literary and Scientific Institution, Bath, UK; MNHN-Muséum National d'Histoire Naturelle, Paris, France; NHMUK - Natural History Museum, London, UK; SMNH—Swedish Museum of Natural History, Stockholm, Sweden.

\section{Anatomical abbreviations}

ang — angular; ant—antorbital; br-branchiostegal rays; cbcranial boss formed by post-parietals and part of the parietals; cl—cleithrum; d. arco—dorsal arcocentra; den—dentary; dpcl一dorsal post-cleithrum; dpto-dermopterotic; dspodermosphenotic; ep 1-6-“epurals" 1-6; ff-fringing fulcra; gp—gular plate; hff—hypaxial fringing fulcra; hp—hypural plate; hsp-haemal spines; io-infraorbitals 1-10; iopinteroperculum; mx-maxilla; na—nasal; no—nasal openings; nsp—neural spines; op—operculum; pa—parietal; phparhypural; pmx — premaxilla; plfr—principal leading fin ray; pop-preoperculum; pp—post-parietal; proc-procurrent rays; psc - pre-supracleithrum; pu 1-7-haemal spines and arches of pre ural vertebrae $1-7$; rode-rostrodermethmoid; sag—supra-angular; sc—scapular; scl—supracleithrum; scrsclerotic ring; scu—scute; smx —supramaxilla; so 1 and 2suborbital 1 and 2; sop—suboperculum; ssc — suprascapular; v. arco—ventral arcocentra; vpcl—ventral post-cleithrum.

\section{Systematic palaeontology}

Superclass Osteichthyes Huxley, 1880

Class Actinopterygii Cope, 1887

Subclass Neopterygii Regan,1925

Order Pachycormiformes Berg, 1937

Family Pachycormidae Woodward, 1895

Genus Pachycormus Agassiz, 1833

Type species. Pachycormus macropterus (de Blainville 1818), originally diagnosed as Elops macropterus.

Diagnosis (emended from Mainwaring 1978). A member of Pachycormiformes presenting the following combination of morphological traits: fusiform in shape; skull roof raised posteriorly into dome-like structure (cranial boss) anterior to post-parietals; mandible with single row of teeth; teeth stout and needle-shaped; two large suborbitals posterior to a series of nine infraorbital bones; pelvic fins absent; dorsal fin in advance of anal fin; base of anal fin not extended.

Pachycormus macropterus (de Blainville, 1818)

Figures 3, 4, 5, 6, 7, 8, 9, 10, 11

Holotype. MNHN-F-JRE 50 (former catalogue number is 10529-10530), nearly complete specimen (incomplete appendicular skeleton and fins) in counterpart.

Specimens studied. BRLSI M1297, BRLSI M1299, BRLSI M1320, BRLSI M1332, BRLSI M1359, BRLSI M1389, BRLSI M1395 (all Pachycormus macropterus); BRLSI M1341, BRLSI M1351, BRLSI M1366, BRLSI M1393 (all Pachycormus).

Diagnosis (emended from Mainwaring 1978). Pachycormus macropterus is a species of Pachycormus presenting 
Fig. 2 A sample of the threedimensional specimens of Pachycormus from Strawberry Bank. a Right lateral view of BRLSI M1297; b ventral view of BRLSI M1359; $\mathbf{c}$ left lateral view of skull of BRLSI M1308. Scale bar for $\mathbf{a}$ and $\mathbf{b}$ equals $30 \mathrm{~mm}$ and $\mathbf{c} 1 \mathrm{~cm}$. Photos by Matt Williams of the BRLSI collections
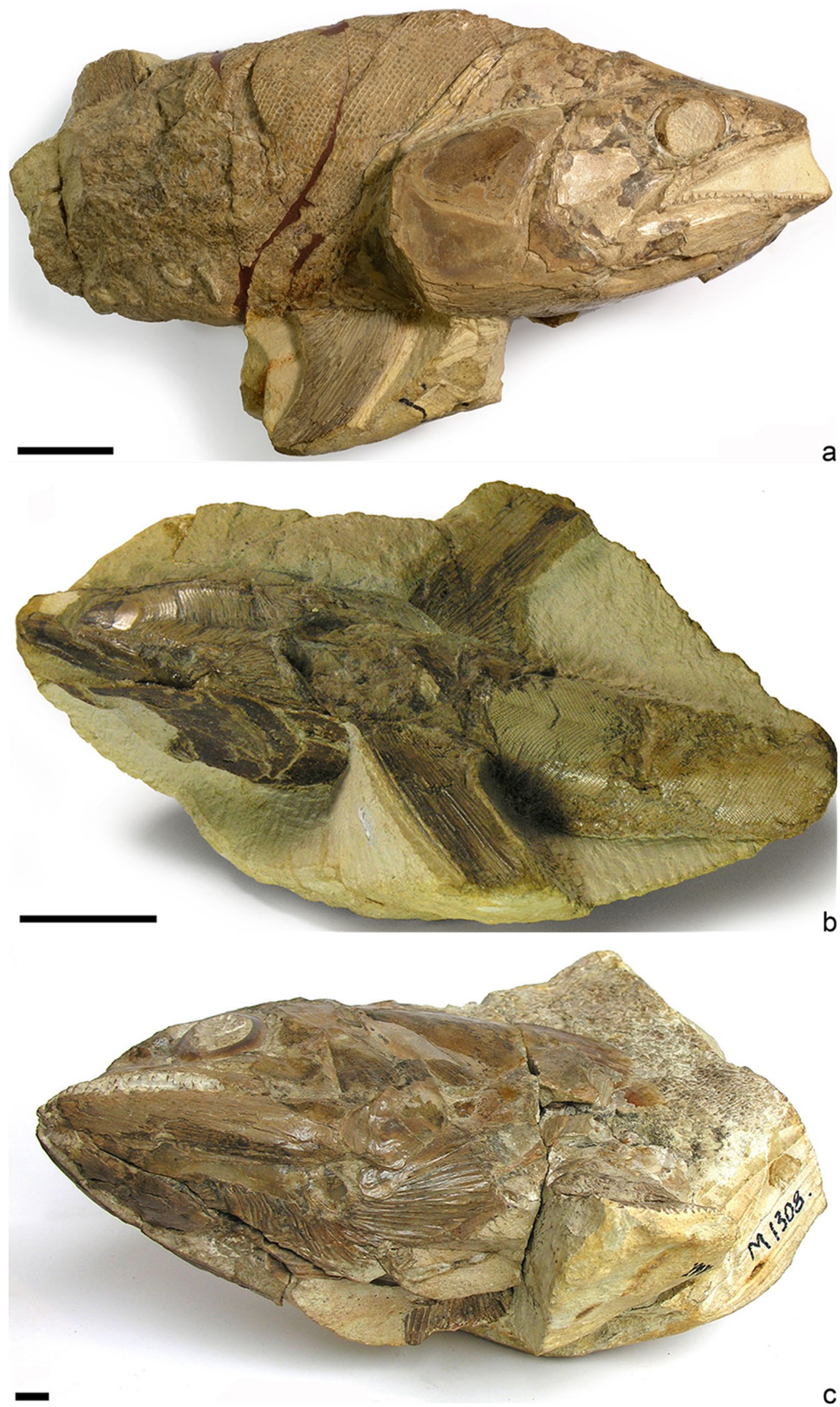
the following features: preorbital region makes up approximately one-third of the skull; opercular bone twice as long as deep, the ventral angle sloping towards the posterior half of the bone.

Remarks. All cranial material studied here belongs to this species.

\section{Description.}

Skull roof-The parietal is a long and wide paired bone covering two-thirds of the dorsal surface of the skull roof above the orbit but not being part of the dorsal orbital margin (BRLSI M1297, BRLSI M1299). The parietals (Figs. 3, 4,5 ) are located posterior to the rostrodermethmoid, and meet medially along an irregular suture. Additionally, the parietals contact the nasal bones at their anterolateral margin. They rise gently backward until they reach a projection, which is named the cranial boss (Figs. 3, 4, 6). This boss is the steepest posterior portion of the parietal bones and is characteristic of members of Pachycormus in general.

In Pachycormus, the post-parietals are small, paired asymmetrical bones which are well separated from each other medially by the parietals and form the posterior portion of the cranial boss (Figs. 3, 4, 5). They are located medial to the dermopterotic (Fig. 3a) and anteromedial to the paired suprascapular bones (Fig. 3b). Post-parietals, nevertheless, are very rarely preserved in the studied specimens, but BRLSI M1395 displays paired post-parietals on the skull roof (Fig. 4).

The dermosphenotics are paired dermal bones with an irregular rectangular outline, which form the dorsal margin of the orbit (BRLSI M1299, BRLSI M1389; Figs. 3, 4, 6). They are located posterior to the nasal bones and anterior to the dermopterotics.

The dermopterotics are paired bones that are located posterior to the dermosphenotic and are usually Y-shaped in Pachycormus when seen in lateral view (Mainwaring 1978) (Fig. 3). This shape can be partially observed in BRLSI M1389 (Figs. 4, 6). However, for most specimens, this shape of the dermopterotic is not preserved because the skulls are substantially crushed in most specimens, where it takes on a more rectangular shape, as can be seen in BRLSI M1332 (Fig. 5). The dermopterotic is situated dorsal to the first suborbital bone (BRLSI M1297, BRLSI M1299).

In Pachycormus, the suprascapulars are usually paired triangular ossifications located posteromedial to the paired post-parietals, with the anterior margins located posterodorsal to the dermopterotics in lateral view (e.g., BRLSI M1332; Figs. 3, 4, 5). Posteriorly, the suprascapular contacts the pre-supracleithrum and supracleithrum.

Snout-The rostrodermethmoid is the most anterodorsal bone on the skull roof (Figs. 3, 4, 5). It is a compound bone, where the rostral part comprises a large, median shield-like bone that is diagnostic of all pachycormids. The anterior-most ventral portion of the rostrodermethmoid bears teeth. These are the lateral bones that constitute the dermethmoid region of the rostrodermethmoid. Toothed lateral-dermethmoids are similar to the condition of the lateral-dermethmoids seen in Siemensichthys macrocephalus (Patterson 1975; Arratia 2000). Fusion to the rostral bone and lack of contact with the parietal is similar to the conditions seen in the Leptolepidae (Patterson 1975). The rostrodermethmoid medially separates the premaxillae from each other, which is typical of pachycormiforms (Woodward 1895; Berg 1940; Wenz 1967; Mainwaring 1978; Lambers 1988, 1992; Kear 2007; Friedman et al. 2010; Arratia and Schultze 2013).

Nasals are located anterior to the dermosphenotics and parietals (e.g., BRLSI M1297, BRLSI M1299, BRLSI M1395; Figs. 3, 4, 5). They lie posterolateral to the rostrodermethmoid in dorsal view. In lateral view, the nasals are small, sub-triangular bones located anterior to the orbit. The nasal openings are situated on the anteroventral margin of the nasal bones (e.g., BRLSI M1297, BRLSI M1299, BRLSI M1395 and BRLSI M1389) and are semi-ovoid in shape (Fig. 6). The nasal bones are located dorsal to the antorbital.

Orbital bones-The antorbitals are small bones with a roughly rectangular outline and which are longer than high (Figs. 3, 4). They are located ventral to the nasal bones, forming the posteroventral margin of the nasal opening (BRLSI M1389; Fig. 6) and dorsal to the premaxilla (BRLSI M1320). Posterior to the antorbitals is the first infraorbital, which is very elongated, forming the ventral margin of the orbit, and is dorsal to the maxilla (e.g., BRLSI M1389; Figs. 3, 6).

The remaining infraorbital bones $2-10$ are rarely preserved in the studied specimens, but when present, they are small, rectangular plate-like ossifications stacked on top of one another, and are located along the posterior edge of the orbit (Figs. 3, 5). The infraorbital plates are fractured, but sutures between bones are still plainly visible.

The two large plate-like suborbital bones lie posterior to the infraorbital series, showing clear sutures between them (Figs. 3, 5). The upper suborbital is trapezoidal in shape, with the ossification becoming broader ventrally. The lower suborbital is triangular in shape and becomes broader posteriorly with a rounded margin. They are located anterior to the opercular series, posterior to the supramaxilla and dorsal to the mandible. A highly ossified sclerotic ring comprising a single plate surrounds the orbit, and it is exceptionally well preserved in some specimens (e.g., BRLSI M1389; Figs. 3, 5). It is located ventral to the dermosphenotic and anterior to the infraorbital series. 
Fig. 3 Reconstruction of the skull of Pachycormus macropterus. a Skull roof; b lateral view of the skull. Scale bar equals $1 \mathrm{~cm}$. Reconstructions are based on Mainwaring (1978)
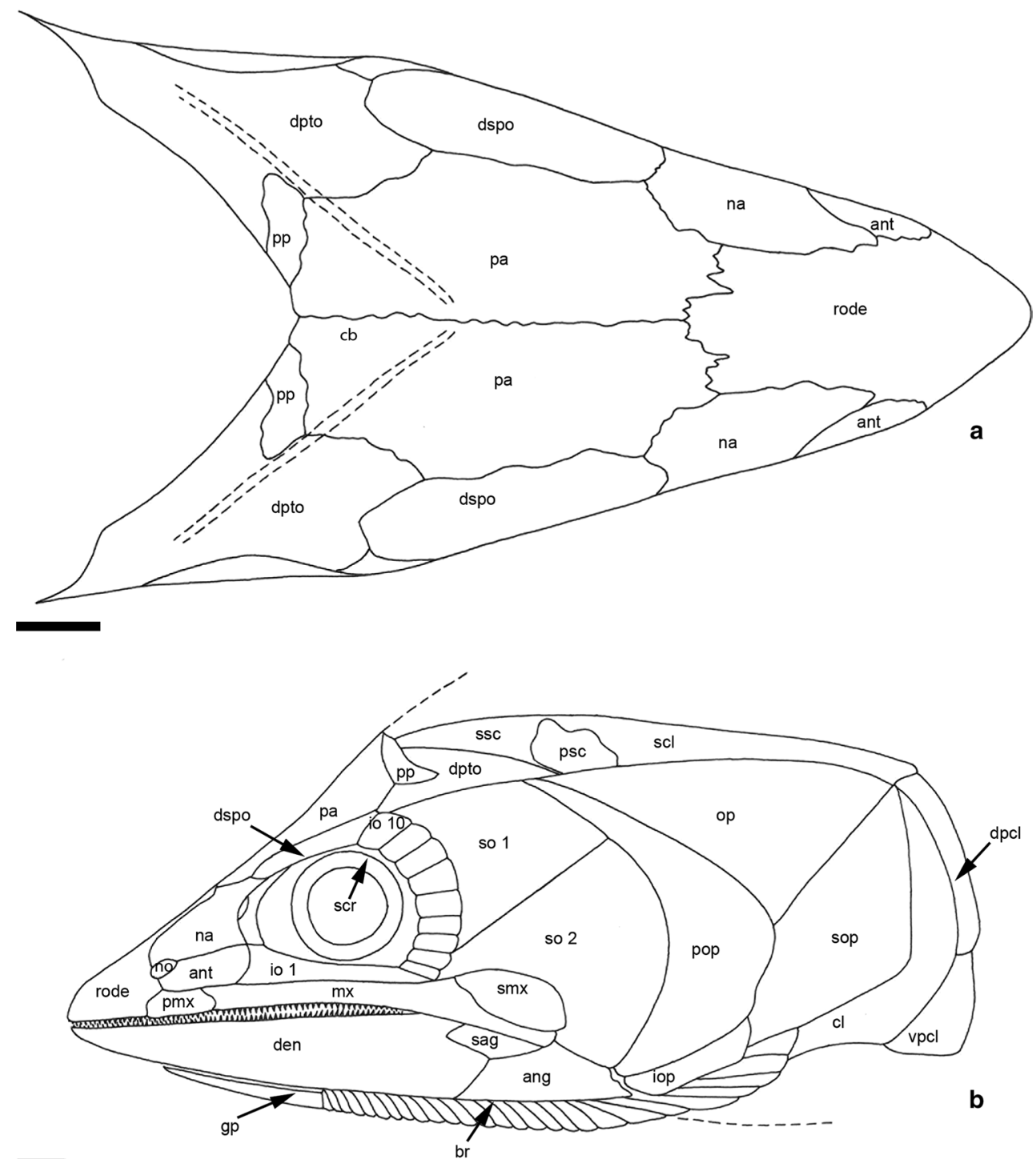

Jaw bones - The upper jaw in most specimens is either fragmented or embedded in the rock to such a degree that it prevents identification. Consequently, the premaxilla, which is a fixed bone (Mainwaring 1978; Kear 2007; Arratia and Schultze 2013), is only rarely preserved in the Strawberry Bank specimens, despite the good overall preservation of the skulls. The premaxilla nevertheless is in excellent condition to be identifiable in a few specimens (e.g., BRLSI M1389; Fig. 6). It is a small ovoid dermal ossification, with the antorbital overlying it dorsally. Anteriorly, the premaxilla fits into a small recess in the posteroventral portion of the rostrodermethmoid. This suturing of the premaxilla to the rostrodermethmoid is a diagnostic character of pachycormiforms (Kear 2007; Arratia and Schultze 2013). A concave notch is present on the anterior border of each maxilla, into which the premaxilla fits. The premaxilla carries a series of needle-shaped teeth that are morphologically identical to those of the rostrodermethmoid but which are less robust than the teeth of the lower jaw (Mainwaring 1978).

The maxilla is an elongate bone which extends beyond the orbit and as far back as the second suborbital (Figs. 3, 5). Anteriorly, it meets the posterior edge of the premaxilla. As it meets the premaxilla, it arches forward and becomes thinner. The posterodorsal portion of the maxilla is deeply excavated to accommodate the supramaxilla. The posterior margin of the premaxilla is convex.

The supramaxilla is an oval-shaped ossification that covers the posterior border of the maxilla (e.g., BRLSI M1299, BRLSI M1395; Figs. 3, 5, 6).

The most anterior bones in the mandible are the dentaries, which cover approximately three-quarters of its total length. The dentaries meet each other at the anterior-most tip from either side, forming a shallow symphysis.

Posterior to the dentaries are the angular and supra-angular bones that meet in an uneven zigzag suture. The angular 
Fig. 4 Pachycormus macropterus, BRLSI M1389 from Upper Lias, Strawberry Bank, Somerset, UK, showing dorsal view of skull roof: a photograph; b camera lucida drawing. Scale bar equals $1 \mathrm{~cm}$
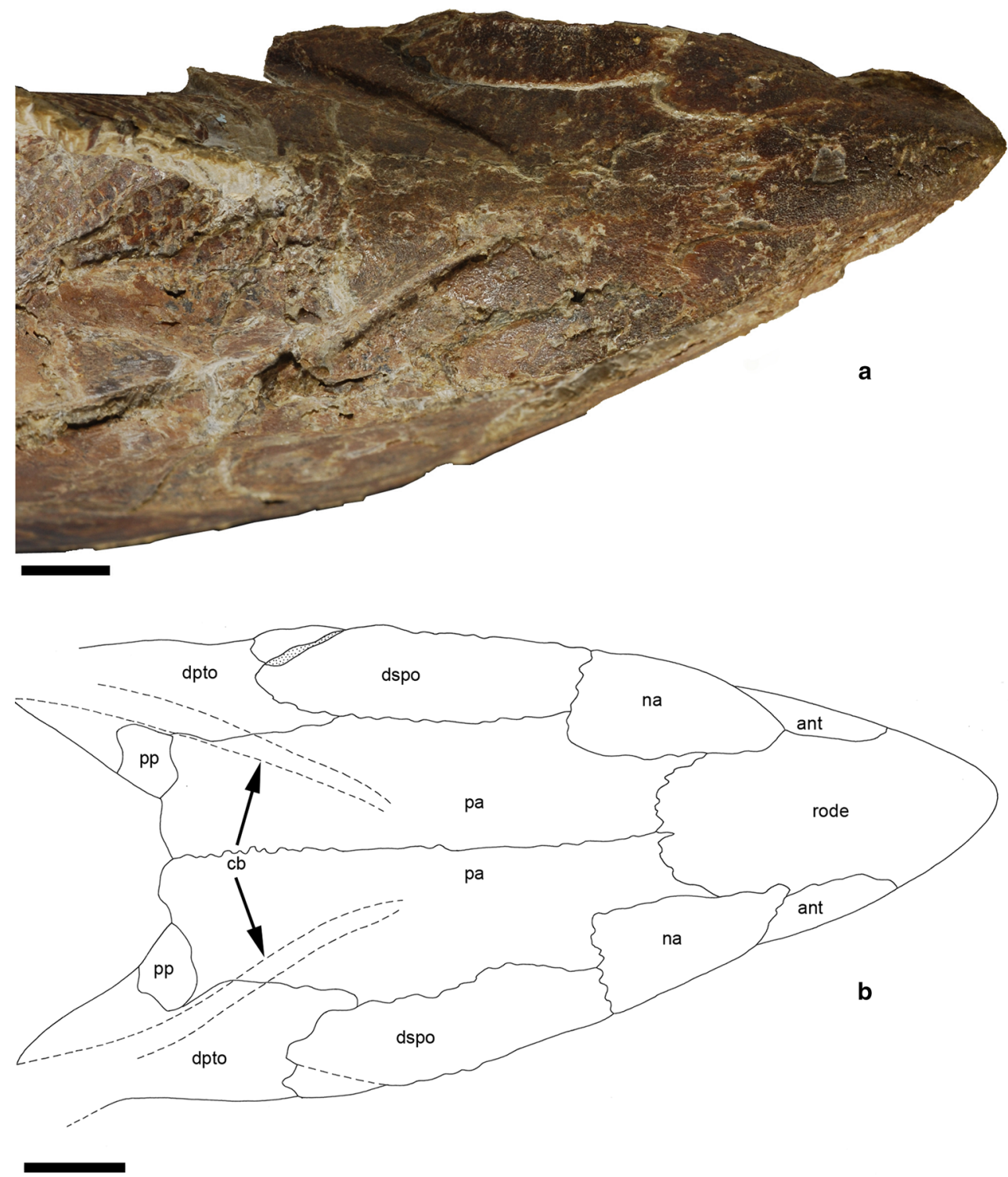

and supra-angular are difficult to distinguish on the majority of specimens, as the surface has flaked away. The angular forms the posteroventral corner of the mandible and articulates with the quadrate (BRLSI M1297; Figs. 3, 5, 7).

The supra-angular is only exposed when the upper jaw is displaced. It is found to be dorsal in relation to the angular and is a small bone bearing a long anterior process with a concave anteroventral notch and a straight ventral margin (BRLSI M1320; Fig. 7). This seems to be a fragmentary supra-angular; however, as it has a wider ventral margin in BRLSI 1332 (Fig. 5), it correlates better with the typical triangular ossification shown in Pachycormus (Fig. 1b; Mainwaring 1978).

The dentition consists of needle-like teeth. The teeth of the dentary are larger, more robust and less numerous than the teeth of the upper jaw. There is almost no variation in the size of the teeth along the margins of either jaw (Figs. 5, 7).

Gular plate-The gular plate is situated anteroventrally in relation to the branchiostegal rays and between the left and right dentary bones (BRLSI M1299, BRLSI M1320; Fig. 7). Radiating ridges are found all around the margin of the gular plate. The gular plate is triangular in form with rounded corners, broadening as it extends posteriorly to the branchiostegal rays.

The branchiostegal rays are a series of elongate, curved bones that support the branchiostegal membrane, completing the opercular series (Figs. 3, 5, 7). They lie ventromedial to the interoperculum and posterior to the gular plate (BRLSI M1299, BRLSI M1320). A total of 66-74 branchiostegal rays are usually present. 
Fig. 5 Pachycormus macropterus, Upper Lias, Strawberry Bank, Somerset, UK, showing lateral view of skull of BRLSI M1332 and pectoral fin of BRLSI M1395. Sensory line pores are represented by dots on the scapular region of the pectoral girdle. a Photograph; b camera lucida drawing. Scale bar equals $1 \mathrm{~cm}$

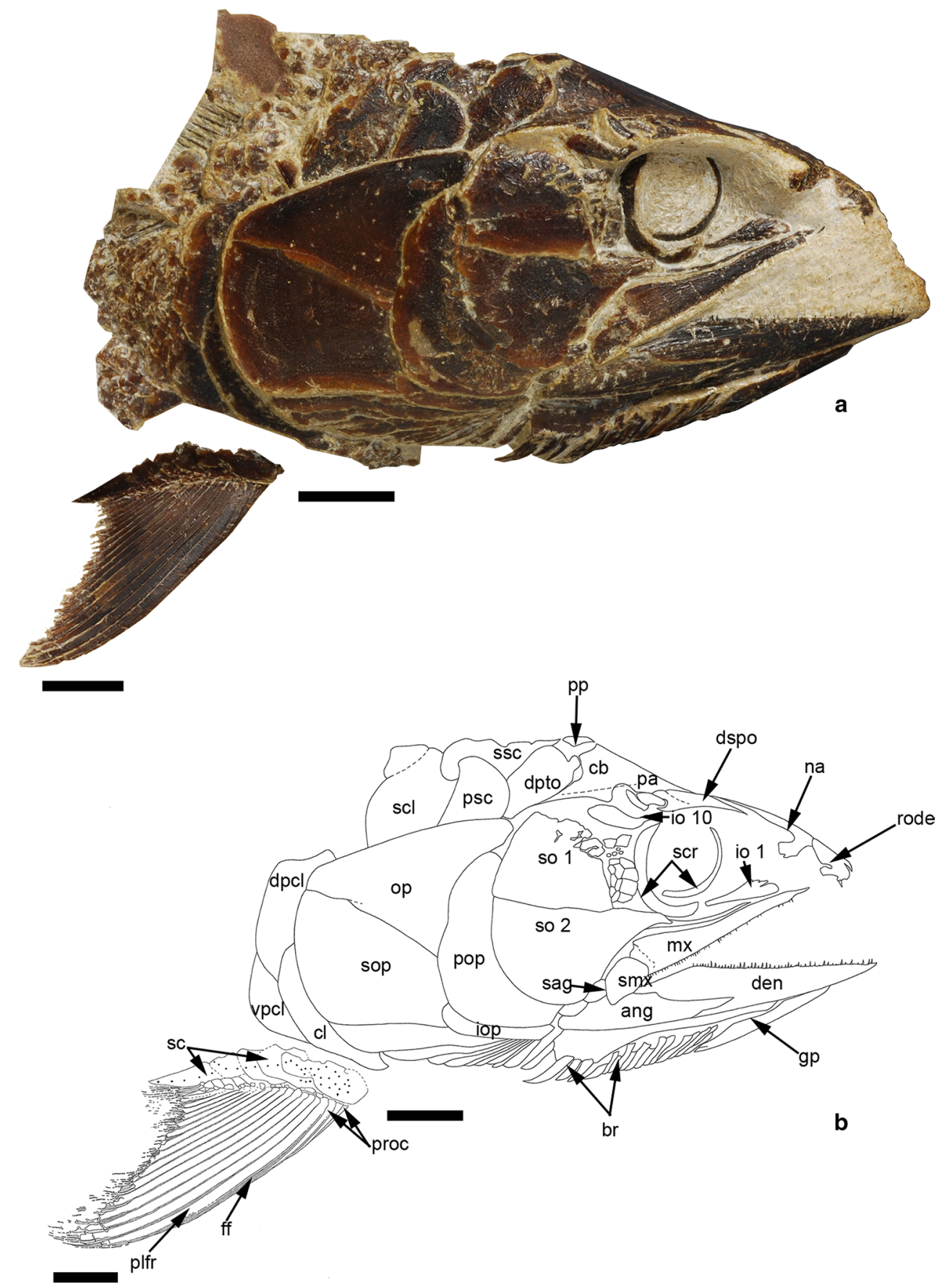

Opercular series-The preoperculum is semi-lunate and has a broad ventral limb (Figs. 3, 5). The preoperculum tapers dorsally to a narrow splint. It is located posterior to the suborbital bones.

The operculum is posterodorsal to the preoperculum, contacting the posterodorsal margin of the preoperculum. It is a large dermal ossification in the shape of a triangle and is dorsal to the suboperculum.

The suboperculum is trapezoidal in shape but becomes deeper posteriorly, with a posteroventral rounded margin
(Figs. 3, 5). The dorsal margin in contact with the operculum is gently sloping. The anterior and dorsal margins are heavily ossified relative to the rest of the suboperculum.

The interoperculum is the smallest element of the opercular series and is rectangular in outline. It is located along the anterior margin of the suboperculum and lies ventral to the preoperculum (Figs. 3, 5). It is positioned dorsally in relation to the branchiostegal rays. 
Fig. 6 Pachycormus macropterus, Upper Lias, Strawberry Bank, Somerset, UK, showing the right side lateral view of BRLSI M1389. Scale bar equals $1 \mathrm{~cm}$

Fig. 7 Pachycormus macropterus, Upper Lias, Strawberry Bank, Somerset, UK, showing ventral view of skull of BRLSI M1320. a Photograph; b camera lucida drawing. Scale bar equals $1 \mathrm{~cm}$
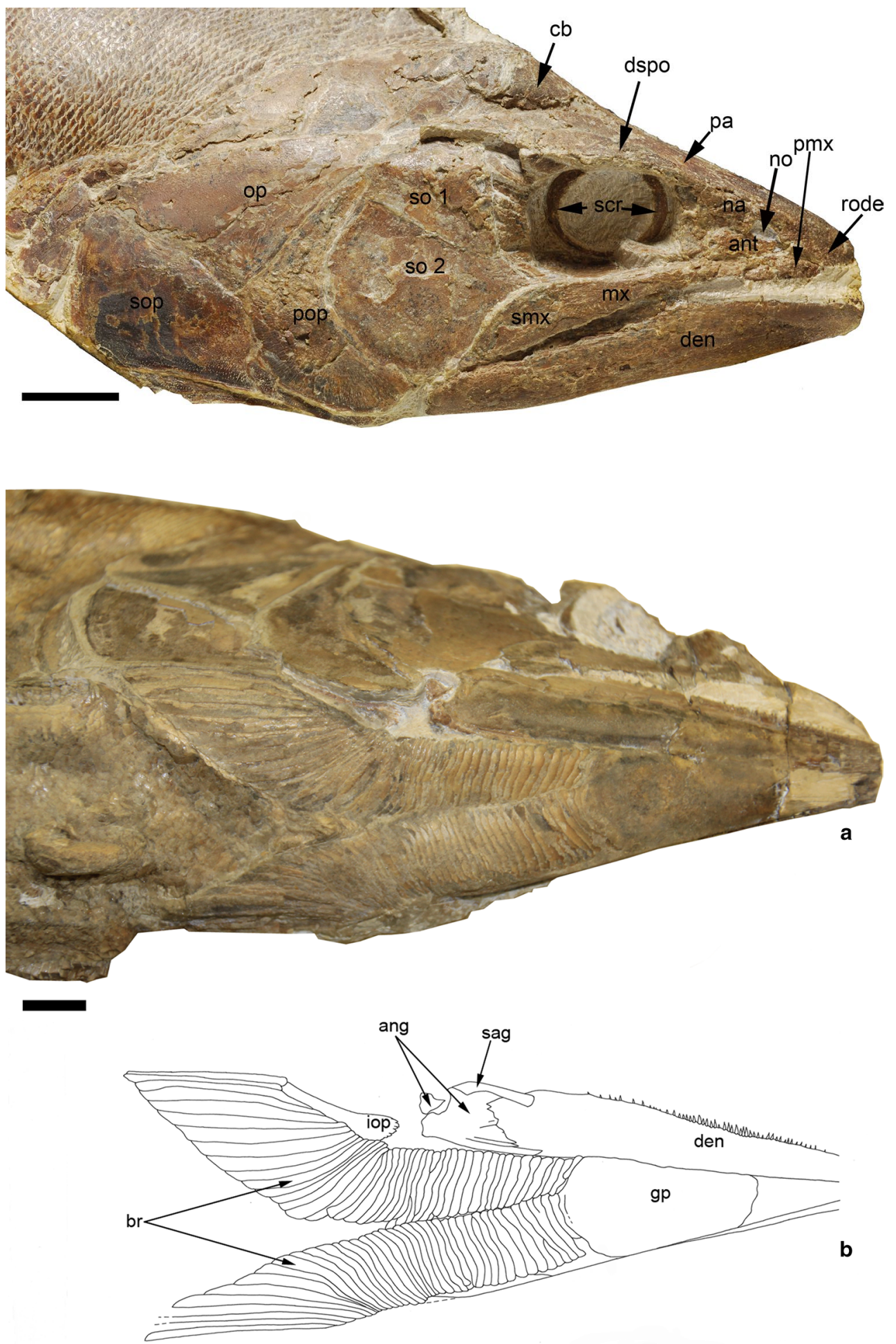

A pre-supracleithrum is preserved ventral to the suprascapular and anterior to the supracleithrum in BRLSI M1332 (Figs. 3, 5). It is a roughly falcate to irregularly shaped ossification with a convex anterior margin.

The supracleithrum is best preserved on the right side in BRLSI M1395 (Fig. 8). It is an elongated thin and blade-like M1395; Fig. 8). 
Fig. 8 Pachycormus macropterus, Upper Lias, Strawberry Bank, Somerset, UK, showing cleithral series on right skull side of BRLSI M1395. Scale bar equals $1 \mathrm{~cm}$
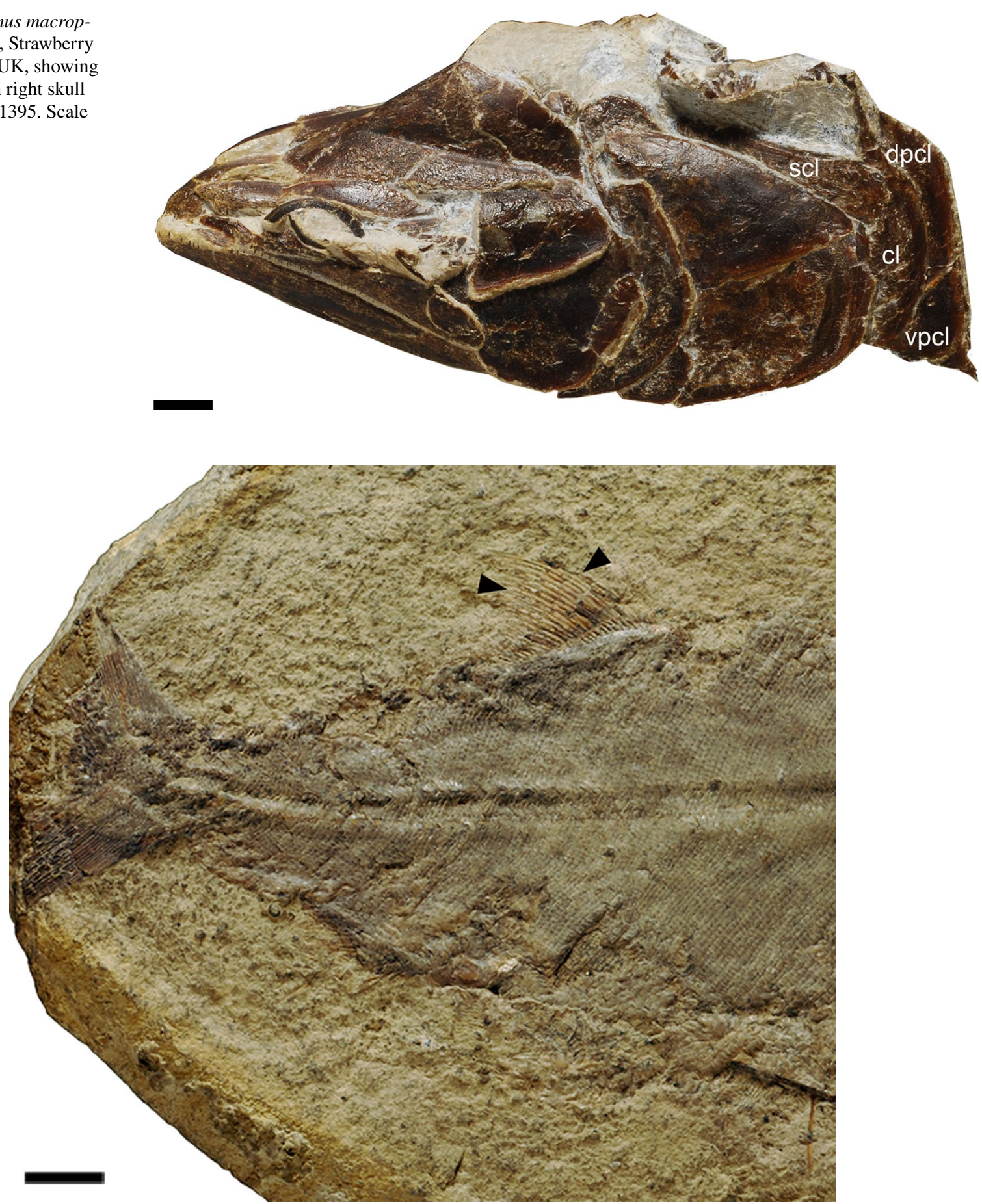

Fig. 9 Pachycormus macropterus, Upper Lias, Strawberry Bank, Somerset, UK, showing dorsal fin of BRLSI M1366. Black arrows indicate position of dorsal fin. Scale bar equals $1 \mathrm{~cm}$

bone with a posterior rounded margin that increases in depth posteriorly. It is located dorsal to the opercular series, with its posterior margin in contact with the dorsal margin of the cleithrum.

Two bones found posterior to the cleithrum visible in BRLSI MI395 are the post-cleithra (Figs. 3, 5, 8). The dorsal post-cleithrum is an elongated plate that is overlain anteriorly by the cleithrum, and the ventral post-cleithrum is a large triangular bone with a convex posteroventral margin.

Appendicular skeleton and unpaired fins-A complete pectoral fin is preserved in specimens BRLSI M1332 and 


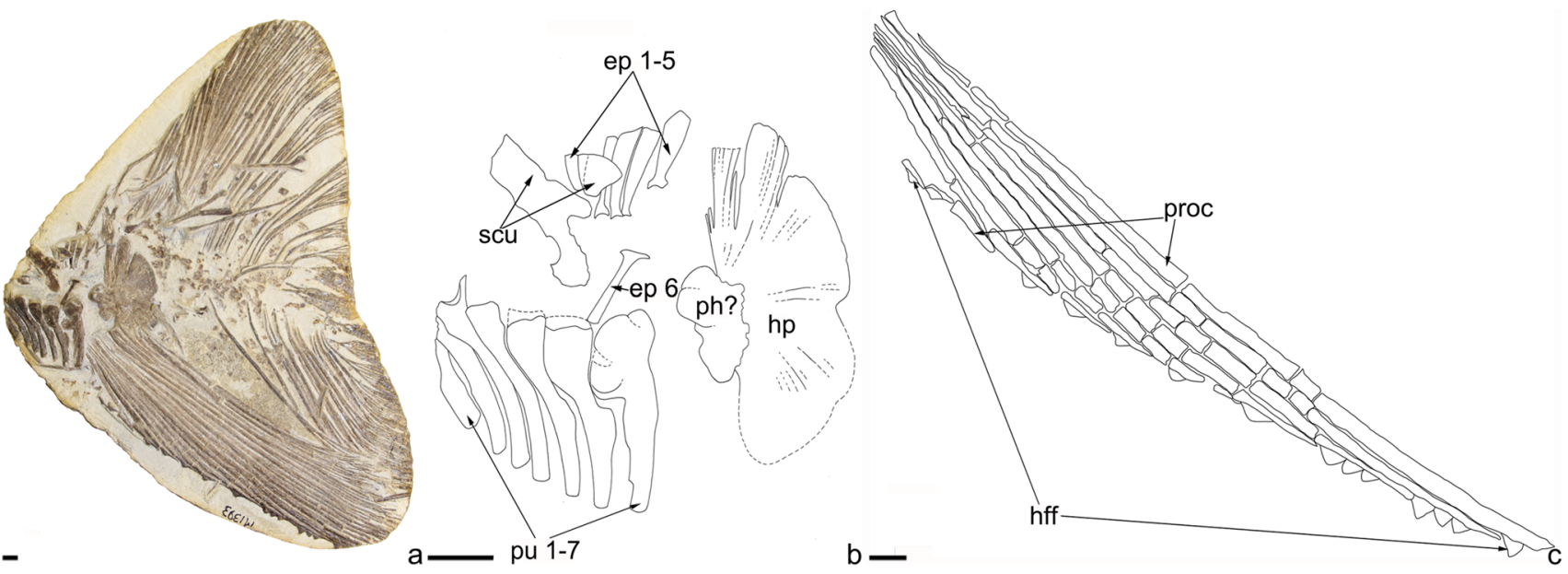

Fig. 10 Pachycormus macropterus, Upper Lias, Strawberry Bank, Somerset, UK. Caudal skeleton of BRLSI M1393. a Photograph; b camera lucida drawing of caudal endoskeleton; c camera lucida drawing of hypaxial fringing fulcra on ventral lobe of caudal fin. Scale bar equals $1 \mathrm{~cm}$

Fig. 11 Pachycormus macropterus, Upper Lias, Strawberry Bank, Somerset, UK. Exposed vertebral column of BRLSI M1389. Scale bar equals $1 \mathrm{~cm}$

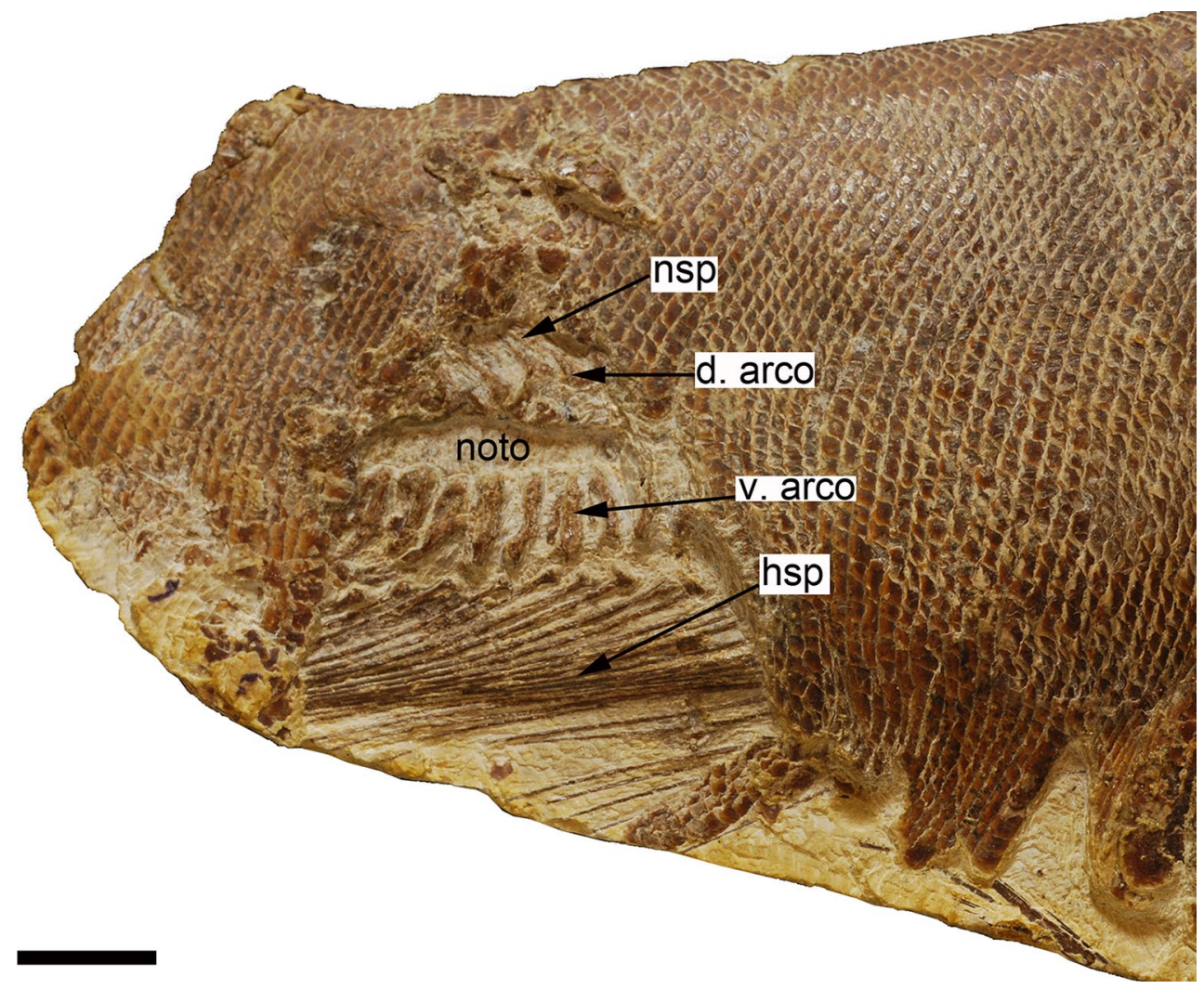

BRLSI M1395 (Fig. 5). It has a characteristic scythe-like shape. Each fin ray shows an anterior dichotomous branching pattern, but there does not appear to be extensive division of the posterior half of each fin ray bifurcation, so the distal edge does not have "a particularly thick fringe", as described by Mainwaring (1978: 83). This could be because the preserved pectoral fins belong to small individuals, so the pectoral fin has not developed to the extent where extensive bifurcation occurs as seen in specimens such as MNHN 10530 (Wenz 1967: fig. 60). As a result, this gives the distal margin of the pectoral fins of BRLSI M1395 a particularly frayed border. Fringing fulcra lie on the surface of the simple principal leading fin ray. These series of fringing fulcra are small spine-like elements, which Arratia (2009) referred to as "Pattern C" fringing fulcra. Anterior to the principal leading fin ray is a series of what can be 
interpreted as either three elongated basal fulcra or procurrent rays. Arratia (2008a) comments that determining the identity of these bones is problematic because of the need for a better understanding of pachycormiform pectoral fin structures. Basal fulcra are usually associated with the caudal fin rather than with paired fins in actinopterygians, and are usually low-lying structures that are lanceolate, leaf-like or arrow-like in shape (Arratia 2009). This description does not match with the structures anterior to the principal leading fin ray, so we have interpreted the structures in BRLSI M1395 as procurrent rays. These procurrent rays have a broad proximal base that narrows as it reaches the distal end. Each procurrent ray increases in length in an anteroposterior direction from the proximal radials.

Since the pectoral girdle of Pachycormus is for the most part endoskeletal, and CT scanning of specimens is outside the scope of this study, we will just discuss the only exposed part of the pectoral girdle present in any of our specimens (BRLSI M1395; Fig. 5), the scapular region. No proximal radials are visible in any of our specimens. The condition of the propterygium, with respect to its fusion to the principal fin ray, also cannot be deduced. This scapular is moderately fragmented, but the general elongated, deep shape of the ossification can be easily deduced. The anterior portion of the scapular has a rounded margin and is overlapped by the ventral post-cleithrum in non-disarticulated specimens (e.g., Mainwaring 1978). The posterior end of the scapular region gently slopes from the midpoint of the ventral post-cleithrum. The posteroventral portion of the bone extends slightly beyond the fin rays. The openings of a sensory canal are identifiable as dotted lines throughout the scapular region, which bifurcates towards the posterior part of the bone, with one line heading in a dorsal direction and the other towards the posteroventral part of the scapular. The number of sensory pores decreases in density posteriorly. Mainwaring (1978: 82) had only this comment regarding this sensory canal: "There is no large scapular foramen beneath the mesocoracoid arch, though a narrow canal does open onto the medial surface of the scapular region."

The dorsal and anal fins are rarely preserved, and they are only visible in specimens BRLSI M1366 (Fig. 9) and BRLSI M1341, respectively. The dorsal fin is small and falcate, containing 23 rays. It is located on the posterior half of the trunk. The anal fin is located close to the caudal fin. It is severely fragmented but seems to have a falcate shape with the distal edge fanning out. No interhaemal spines are present between the haemal spines and the anal fin rays. Thirteen fin rays are preserved in the anal fin.

The caudal fin is homocercal (e.g., BRLSI M1393; Fig. 10) and carries 70 fin rays that articulate with the hypural plate. The fin rays of the dorsal and ventral lobes of the caudal fin are segmented and bifurcate dichotomously at their distal tips. In BRLSI M1393, the ventral lobe has the fin rays preserved in what must have been their original condition while still alive. Dorsal lobe fin rays are fragmented and overlap one another. The true distal tips of the fin rays of the dorsal and ventral lobes are absent in BRLSI M1393 because they protrude beyond the posterior edge of the enclosing nodule. The middle portion of the fin also shows a change in pattern in the fin rays. While they retain their segmentation, the rays become thinner and branch out continuously, which results in brush-like tips at the distal end of the rays. The principal caudal fin ray cannot be identified, as the caudal fin rays are not fully preserved, being broken off by the posterior margin of the nodule.

The hypural plate is a large, almost fan-shaped compound bone made up of an undetermined number of hypurals (Wenz 1967; Arratia and Lambers 1996) that broadens posteriorly with rounded margins and is overlain by hypaxial fin rays in its ventral portion (Fig. 10), whereas in a less taphonomically distorted specimen this would have been overlain by both epaxial and hypaxial fin rays (Arratia and Lambers 1996). It is located posterior to the preural vertebrae. In other specimens (Patterson 1973; Mainwaring 1978), the hypural plate is ventral to the "epurals", but in BRLSI M1393 the hypural plate is directly posterior to the "epurals". This position is a result of the postmortem burial process, which has fragmented and transported an assortment of bones in this specimen. This same process appears to account for what seems at first to be the fusion of two hypural bones at the dorsal margin of the hypural plate. However, no sutures are present to suggest fusion, indicating that the impression of a fusion event is created by two splits along the dorsal margin of the hypural plate (Fig. 10b). Along the base of the hypural plate is what appears to be an medial bone with a club-shaped head and a smaller ventral extension with rounded margins. A suture between this bone and the hypural plate indicates what we interpret to be a possible parhypural.

The series of preural vertebrae is anterior to the hypural plate (Fig. 10). In other specimens, these bones are overlapped by the hypaxial principal fin rays (Wenz 1967; Mainwaring 1978; Arratia and Lambers 1996), but here displacement seems to have raised the preural vertebrae above the fin rays. The morphology of these bones and their position relative to the hypural plate is an indication that they are preural vertebrae despite their lack of overlap by fin rays. The preural vertebra anterior to the hypural plate is curving gently backward. It is a large, narrow bone with a greatly expanded ventral arcocentrum with a rounded tip. On first inspection, it looks as though the ventral portion of the dorsal expansion spreads outward anteriorly. Upon closer observation, the anterior half of the dorsal expansion is crushed in, forming a groove that gives the impression of a projection. 
The rest of the preural vertebrae share the large, rounded dorsal head of the anterior-most preserved bone, but here the anterior projection is very evident. The preceding preural vertebrae curves slightly more than the first bone, whereas each successive haemal spine curves backward more strongly as they face anteriorly toward the trunk vertebrae. Only the arcocentra of the first four preserved preural vertebrae are present in BRLSI M1393, as the last two are cut off at the edge of the nodule. As the spines face anteriorly towards the trunk vertebrae, they are raised substantially higher than the rest of the caudal endoskeleton as a result of the burial process.

A large scute is displaced anteriorly to the "epurals" (Fig. 10). It is heavily fragmented, but appears to broaden posteriorly and possesses a convex ventral margin, which gives it a rhomboid shape similar to that seen in a Lower Toarcian Pachycormus specimen from Holzmaden, Germany, SMNH SW P.6152 (Arratia and Lambers 1996). The scute is usually found anterior to the "epurals" but has moved inward to cover the "epurals" following distortion.

The bones classified as "epurals" in the caudal fin of Pachycormus may not be epurals due to the revised definition of these bones given by Arratia and Schultze (1992), which they used to refer to detached neural spines of the preural and ural vertebrae. Since the development and homology of these structures is still unknown, Arratia and Schultze (1992) suggest they be referred to as "epurals" until such homology has been demonstrated. We will be following the same naming convention when referring to these bones. Six "epurals" are present in BRLSI M1393 (Fig. 10). Previous descriptions of the caudal endoskeleton of Pachycormus revealed seven "epurals" (Patterson 1973; Arratia and Lambers 1996). It is possible that more "epurals" are present, but that they are overlain by the scute or have been lost during burial. Five "epurals" are located anterodorsal to the hypural plate. The "epurals" have an expanded base that narrows in a ventrodorsal direction and begins to expand laterally as it reaches the dorsal margin of the bone. The dorsal margin has a flat surface with rounded edges, and the dorsal margins become broader in a posterior direction towards the hypural plate. A roughly ovoid fragment of bone, most likely part of the scute, overlies "epurals" 2 and 3. A displaced "epural" is situated ventral to the "epurals", with its proximal surface facing dorsal side up. The expanded base of this displaced "epural" has a projecting anterior process.

In other specimens, all "epurals" except "epurals" 2 and 3 articulate with ural neural arches (Arratia and Lambers 1996), but no ural neural arches appear to be preserved in any of the caudal fin specimens, and so articulation cannot be shown.

At least 12 hypaxial fringing fulcra are located along the ventral margin of the caudal fin. The five anterior-most fringing fulcra are found singly along the anteroventral margin of the leading edge of each procurrent caudal fin ray. The fringing fulcra have an expanded base that narrows towards the distal end in a rounded tip. The posterior-most fringing fulcra cluster together in groups of three along the posteroventral margin of the procurrent ray, with the exception of one fulcrum found on the posterior margin of the nodule. These posterior-most fringing fulcra have a pointed instead of a rounded tip (Fig. 10c). Epaxial fringing fulcra are not preserved on any of the caudal fins.

In BRLSI M1341, the lateral line is shown terminating dorsally into the axial lobe before the caudal fin.

Axial skeleton-Most specimens have scales covering nearly all of the trunk, so that the vertebral column is difficult to examine. One specimen, BRLSI M1389, however, has a part of its flank covering the vertebral column removed (Fig. 11). A few dorsal and ventral arcocentra are exposed. The ventral arcocentra are flattened and become broader posteriorly, but their elongate shape is evident, along with their ventral arches being curved in a posterior direction. There are 25 haemal spines visible in this specimen, which are strongly curved in a posterior direction. The base of some of the haemal spines widens to a fan shape, which we interpret to be disarticulated haemal arches. The high number of haemal spines exposed, along with the close proximity to the pectoral girdle, suggests that these spines are paired ribs. The specimen shows only four dorsal arcocentra, which appear to be less distorted by taphonomic processes and display a similar fan-shaped neural arch. From what little is shown of the neural spines, their morphology is similar to the haemal spines. Eight-nine neural spines are preserved. The space between the dorsal and ventral arcocentra is the unossified notochord.

Squamation-Body scales of Pachycormus are of amioidtype sensu Schultze $(1966,1996,2008)$ (specimens BRLSI M1366 and BRLSI M1395). The scales of Pachycormus, as is seen in all pachycormids with scales, are small and rhombic-shaped. Each scale is a thin bony basal plate with striations. The anterior portion of the scale structure is ornamented by extremely thin radiating ridges with closely packed growth lines appearing on the posterior region, giving it a superficial resemblance to the concentric ridges of cycloid scales (Schultze 1966; Wenz 1967: fig. 64). The ridges are extremely thin, unlike those seen in amioid scales of fishes from the family Amiidae (Schultze 1996; Meunier and Brito 2004), but their anterior position on the scale is similar to that seen in other amioid-type scales. The reduced size of the scales is a common characteristic of pachycormids (Lambers 1992). Rounded edges found in well-preserved scales show a superficial resemblance to cycloid scales. Ganoin is absent from the scales, another 
characteristic of most pachycormids (Schultze 1966, 2016; Lambers 1992).

\section{Discussion}

The caudal fin described here reveals that it differs in some respects from accounts described in other specimens of Pachycormus in the literature (Wenz 1967; Mainwaring 1978; Bartsch 1988; Arratia and Lambers 1996). These differences will be described in detail below, as will the taxonomic status of the specimens studied here and what it implies for the state of Pachycormus systematics. Also discussed will be the relationship of Pachycormus to the most enigmatic members of Pachycormiformes, the giant suspension feeders.

Remarks on the caudal fin-BRLSI M1393 (Fig. 10) from Strawberry Bank presents the best-preserved caudal endoskeleton in the Bath collection and will be used here to compare it to other caudal endoskeletons of Pachycormus that have been described previously. While there is quite significant displacement of the fin rays and bones due to taphonomic displacement, there are still numerous morphological and quantitative differences in the caudal endoskeleton that warrant a comparison between BRLSI M1393 and other described Pachycormus caudal fins from the literature. The caudal endoskeleton of Pachycormus described by Mainwaring (1978: pl. 30) has a hypural plate and a ventral hypural with a broad proximal base that narrows towards its distal end and is posterior in relation to the preural vertebrae ("haemal arches and spines"). There are also four free reduced hypural plates lying along its dorsal margin. These separate hypurals are not observed in BRLSI M1393 (Fig. 10).

Bartsch (1988: Fig. 36a) described a hypural plate and a separate dorsal element (hypural?) in Pachycormus bollensis associated with a chordacentrum. No such chordacentrums or dorsal elements are present in the Bath specimens. When Arratia and Lambers (1996) investigated the caudal fin of specimen SMNH P.6152, they observed that the median arch at the base of the hypural plate was in a similar position as the vertebrae preceding it. The ventral arcocentrum of preural vertebra 1 was found to be included in the hypural plate, forming a compound structure. The ventral anterior portion of this compound structure has expanded laterally and thickened similarly to the condition seen in the preceding preural vertebra. This compound structure is not observed in BRLSI M1393.

The parhypural described in SMNH P.6152 by Arratia and Lambers (1996: fig. 4b) is fused ventrally to the hypural plate and is suggested as the most likely site where the caudal region of the notochord and nerve cord could have run.
In BRLSI M1393, we interpret a more medial fusion in the hypural plate and the bone directly medial to its base of the hypural plate as the parhypural, with the suture between the two bones as a sign of fusion between them.

Wenz (1967) noted a hypural plate that was perfectly symmetrical articulating with the fin rays of the dorsal lobe in the caudal skeleton of Pachycormus curtus (MNHN 1872493). We cannot observe such perfect symmetry in BRLSI M1393 because the limestone is lifted and fragmented. Such a hypural plate is seen in BRLSI M1351, which suggests that such symmetry might have been found in BRLSI M1393 before burial.

The "epurals" also differ in the examined specimens from BRLSI M1393. The reconstruction in Mainwaring (1978) showed the six "epurals" becoming more elongated, narrow and curved forward. The anterior "epurals" do not have the broad dorsal head that is seen in BRLSI M1393. In the specimens studied by Arratia and Lambers (1996), the "epurals" have broad proximal bases, with the exception of "epurals" 2 and 3, unlike the laterally expanded but narrow bases of the "epurals" in BRLSI M1393. "Epural" 1 (SW P.1652; Arratia and Lambers 1996) is notable in its lateral expansion and sigmoid shape. In the specimen SW P.6152 there is an articulation with the margins of the "uroneurals" or two neural spines. There is a seventh "epural" that is small and almost completely covered by the base of the fin rays and which articulates with the distal margin of "uroneural" 2 (Arratia and Lambers 1996: fig. 4b). It is impossible to identify whether the "epurals" articulated with them, because "uroneurals" and neural spines are not preserved in BRLSI M1393. No epaxial elements such as neural arches and spines, "uroneurals" or "epurals" were available for study in the specimens of Pachycormus curtus (Wenz 1967).

Haemal arches of the preural vertebrae as reconstructed by Mainwaring (1978: fig. 28) have a broad head with rounded margins, while the haemal spine narrows towards its distal end and becomes more strongly curved backward and elongated in an anterior direction. Since the most anterior preural vertebrae are not present in BRLSI M1393, it is difficult to determine whether there is any substantial difference between it and Mainwaring's specimens. We do not know whether the seventh preserved preural vertebrae expanded laterally in the middle while contracting at the ends, as shown by Mainwaring (1978). Otherwise, there is no difference in the preural vertebrae between BRLSI M1393 and the specimens studied by Mainwaring (1978).

Another characteristic of these bones is that the head not only becomes narrower in a posterior direction, but the preserved preural vertebrae 4-6 also possess a flattened dorsal margin, as can be seen in NHMUK P.59545 (Mainwaring 1978: pl. 30). Arratia and Lambers (1996: fig. 4b) observed that the head of the preural vertebrae are broad and become more laterally expanded in a posterior direction 
in the Pachycormus specimen SMNH P.6152. However, in another Pachycormus specimen, SMNH P.6151 (Arratia and Lambers 1996: fig. 5), the head of the preural vertebrae increases in size posteriorly. There are a larger number of preural vertebrae articulating with hypaxial rays and fulcra in SMNH P.6151 and SMNH P.6152 (Arratia and Lambers 1996) than observed in MNHN 1872-493 (Wenz 1967). No preural vertebrae bear hypaxial rays and fulcra in BRLSI M1393 due to displacement of fin rays.

A scute was observed in the Pachycormus specimens studied by Arratia and Lambers (1996), being rhomboid in SMNH P.6152, similar to BRLSI M1393, and ovoid in SMNH P.6151. The single scute in both of these Holzmaden specimens is located dorsal to the "epurals".

The large range of morphological variation and shape differences in caudal fins of Pachycormus suggests that there are conflicting interpretations regarding the systematics of this pachycormid. Mainwaring's thesis (1978) was mainly on Pachycormus macropterus, but when it came to describing the caudal fin, it was described as belonging to Pachycormus sp. Arratia and Lambers (1996) referred both SMNH P.6151 and SMNH P.6152 to Pachycormus sp., where differences in the shape of ventral arcocentra of the preural vertebrae and scute shape might suggest species-level differences. Wenz (1967) identified the investigated caudal skeleton as belonging to Pachycormus curtus. In terms of the shape of the hypural plate, it is clearly different from the hypural plate and reduced hypurals described by Mainwaring (1978). Despite the fragmentation, the hypural plate of BRLSI M1393 seems to be more similar to the hypural plate of MNHN 1872-493 described by Wenz (1967). As indicated above, BRLSI M1351 seems to even more closely resemble MNHN 1872-493. It is, however, premature to assign the caudal fin described by Wenz (1967) to Pachycormus curtus or to any other species of Pachycormus. Lindkvist (2012) added Pachycormus bollensis to the Friedman et al. (2010) analysis, and found that the one unique character in its caudal fin was character 78 (uppermost hypaxial-caudal rays), which was coded as 0 (fin-rays successively shorter from bottom to top). In contrast, the same character for Pachycormus $\mathrm{sp}$. was coded as 2 (dorsal and ventral fin-ray bases symmetrical).

A recent morphometric study on Pachycormus by Wretman et al. (2016) reveals that specimens that were considered $P$. curtus were actually smaller specimens of $P$. macropterus, and $P$. curtus is now considered a junior synonym for P. macropterus. Proportional traits used to distinguish Pachycormus species, such as opercular height/length ratio and maximum cranial length/total body length, are consistent along an ontogenetic morphocline. Pachycormus bollensis specimens used in this study were indistinguishable from $P$. macropterus with phylogenetic character-state frameworks, while the holotype of $P$. bollensis has been re-identified as
Saurostomus esocinus (Woodward 1895). It is now suggested that $P$. macropterus is the sole species of the genus Pachycormus.

The variability observed in caudal endoskeletons between BRLSI M1393 and the specimens described by Wenz (1967), Mainwaring (1978), Bartsch (1988), and Arratia and Lambers (1996) suggests that the diversity of Pachycormus may be greater than realized. Ecologically, the caudal fin is of great importance to Pachycormus as an open ocean swimmer, and this variety in caudal endoskeletons suggests either different species or evolutionary transitions from one state to another. In the future it may be important to focus on caudal fin characters of articulated specimens to diagnose not only Pachycormus species but other members of Pachycormiformes.

Comments on the phylogenetic relationship of Pachycormus to other pachycormiforms-Pachycormus is the best-known member of the family Pachycormidae, and the specimens described here add some new information to previous studies. In a phylogenetic overview of the family by Friedman (2012), which included 15 pachycormid taxa and 121 characters, only four characters of Pachycormus were marked as unknown. This was in great contrast to other taxa such as Leedsichthys, which had 94 characters marked as unknown and 20 as known (the rest were inapplicable). One of the characters coded unknown in the Friedman analysis is character 69 ["Supramaxilla position $[L, L i, F]$ : (0) Dorsal to maxilla; (1) Posterodorsal to maxilla"; Friedman 2012: supp. mat. p. 7]. However, the supramaxilla was also looked at in the phylogenetic analyses of Arratia (2008b, 2013, 2016, 2017), who coded the position of the supramaxilla as posterodorsal to the maxilla (1). Sferco et al. (2015) have also coded the supramaxilla position as (1) in their phylogenetic analysis. Our sample of Pachycormus specimens (BRLSI M1299, BRLSI M1395) further confirms the coding by these authors. Another unknown character coding was character 115 regarding the presence or absence of bifurcations in pectoral fin rays. BRLSI M1395 does indeed show bifurcations in the pectoral fin rays; however, Friedman (2012) does code for this in character 116 ["Bifurcations of pectoral lepidotrichia occurring independently of joints $[L, L i, F]:(0)$ Absent; (1) Present"; Friedman 2012: supp. mat. p. 8]. None of the characters present in our sample reveal new character states for the other two unknown characters in the analysis by Friedman (2012): character 23 ["Vertebrae fused into adult occipital condyle [G10]*: (0) Absent; (1) Present"; Friedman 2012: supp. mat. p. 5] and character 99 ["Caudal diplospondyly [GML]*: (0) Absent; (1) Present”; Friedman 2012: supp. mat. p. 8].

Previous phylogenetic analyses of the pachycormids showed that Pachycormus is sister taxon to the suspensionfeeding pachycormids (Friedman 2012; Lindkvist 2012) or 
more derived than the basal pachycormid Euthynotus (Wretman et al. 2016). The analysis by Lindkvist (2012) showed that there are three distinct ecological guilds within Pachycormidae: (1) the hyper-carnivores with large cutting canines (e.g., Hypsocormus and Protosphyraena), (2) the generalist predators with short grasping teeth (e.g., Pachycormus and Saurostomus) and (3) the suspension feeders (e.g., Leedsichthys and Bonnerichthys). However, recent work on a hypercarnivorous pachycormiform Protosphyraena reveals it to be a derived suspension feeder, indicating an extraordinary reversal in transformative states of the dental characters during evolution (Liston and Maltese 2017). Friedman (2012) described Ohmdenia, with its stout, low-crowned dentition in multiple rows, as an intermediate form between generalized predators and suspension feeders. Similar tooth morphologies are found in whales and marine reptiles that specialize in soft-bodied prey such as cephalopods (Massare 1987). In the cladistic analysis, it was the closest sister taxon to the suspension feeders. Pachycormus is the sister taxon to Saurostomus, which in turn is sister to Ohmdenia and filter feeders, which correlates with their appearance in the fossil record (Friedman 2012: fig. 2a). Suspension-feeding pachycormids are also the most incompletely preserved members in the family, which explains their low bootstrap support in cladistics analyses (Liston 2006, 2013; Lindkvist 2012; Liston et al. 2013). This is in contrast to those of the hyper-carnivores, which have very strong bootstrap values (Lindkvist 2012). This evolutionary model suggests that Pachycormus is part of a lineage within the pachycormiforms that reduces its dentition through evolutionary time while switching to a planktivorous diet. The alternative parsimonious phylogenetic tree produced by Wretman et al. (2016) using Friedman's (2012) data showed Pachycormus as being basal to all pachycormiforms with the exception of Euthynotus (Wretman et al. 2016: figs. 3b, 4). According to the authors, this makes the genus a "monospecific basal "wildcard" due to Pachycormus having a mosaic of characters representative of both filter feeding and hyper-carnivore clades.

\section{Conclusion}

Pachycormiformes is still, for the most part, a poorly understood order, with most specimens greatly fragmented and many with specific parts of the morphology unknown. Despite being the best-known taxon of the pachycormids, Pachycormus is also incompletely understood. The morphology of the caudal skeleton in the specimens studied here indicates either intra- or interspecific variations, which should be a focus of future work. This also has created controversy in terms of it conflicting with the ideas presented by Wretman et al. (2016) that Pachycormus is represented by a single species only. Morphological characters should be considered alongside morphometric studies to determine whether a taxon should be lumped or split into different species. However, the future of pachycormiform study rests on finding more complete and better-preserved specimens of the congeners of Pachycormus such as members of the suspension-feeding clade and Ohmdenia. These wonderfully preserved specimens can also provide an excellent opportunity for future research such as CT scanning to reveal internal anatomy, a rare source of phylogenetic data in fossil actinopterygians, and could help further elucidate their phylogenetic position with regard to Teleostei.

Acknowledgements Open access funding provided by University of Vienna. We are deeply indebted to Matt Williams (BRLSI) for granting access to the Strawberry Bank specimens under his care. Additionally, we thank Lorie Barber, formerly of Bristol City Museum, for her excellent preparation work on the fossil fishes, Simon Powell (University of Bristol) for photographing the specimens, Paul Lambers and Jeff Liston (University of Glasgow) for locating literature difficult to access, Norbert Frotzler (University of Vienna) for illustrating the figures, and finally, Gloria Arratia (University of Kansas) for giving very helpful feedback during the preparation of this manuscript. The project on the Jurassic Ecosystem of Strawberry Bank, Ilminster (JESBI), has been generously funded by the Esmée Fairburn Foundation and the Leverhulme Trust (grant RPG-2015-126).

Open Access This article is distributed under the terms of the Creative Commons Attribution 4.0 International License (http://creativeco mmons.org/licenses/by/4.0/), which permits unrestricted use, distribution, and reproduction in any medium, provided you give appropriate credit to the original author(s) and the source, provide a link to the Creative Commons license, and indicate if changes were made.

\section{References}

Agassiz, J.L.R. 1833-1844. Recherches sur les poissons fossiles. Neuchâtel: Imprimerie Petitpierre.

Arratia, G. 2000. New teleostean fishes from the Jurassic of southern Germany and the systematic problems concerning the 'pholidophoriforms'. Paläontologische Zeitschrift 74 (1-2): 113-143.

Arratia, G. 2004. Mesozoic halecostomes and the early radiation of teleosts. In Mesozoic fishes 3-systematics, paleoenvironments and biodiversity, eds. G. Arratia and A. Tintori, 279-315. München: F. Pfeil.

Arratia, G. 2008a. Actinopterygian postcranial skeleton with special reference to the diversity of fin ray elements, and the problem of identifying homologies. In Mesozoic fishes 4-nomenclature and homology, eds. G. Arratia, H.P. Schultze, and M.V.H. Wilson, 49-101. München: F. Pfeil.

Arratia, G. 2008b. The varasichthyid and other crossognathiform fishes, and the break-up of Pangaea. Geological Society, London, Special Publications 295 (1): 71-92.

Arratia, G. 2009. Identifying patterns of diversity of the actinopterygian fulcra. Acta Zoologica 90 (1): 220-235.

Arratia, G. 2013. Morphology, taxonomy, and phylogeny of triassic pholidophorid fishes (Actinopterygii, Teleostei). Journal of Vertebrate Paleontology 33 (6): 1-138. (Society of Vertebrate Paleontology Memoir 13). 
Arratia, G. 2016. New remarkable Late Jurassic teleosts from southern Germany: Ascaloboidae n. fam., its content, morphology, and phylogenetic relationships. Fossil Record 19: 31-59.

Arratia, G. 2017. New Triassic teleosts (Actinopterygii, Teleosteomorpha) from northern Italy and their phylogenetic relationships among the most basal teleosts. Journal of Vertebrate Paleontology 37 (2): e1312690.

Arratia, G., and P. Lambers. 1996. The caudal skeleton of pachycormiform fishes: parallel evolution? In Mesozoic fishes-systematics and paleoecology, eds. G. Arratia and G. Viohl, 191-218. München: F. Pfeil.

Arratia, G., and H.P. Schultze. 1992. Reevaluation of the caudal skeleton of certain actinopterygian fishes: III. Salmonidae. Homologization of caudal skeletal structures. Journal of Morphology 214 (2): 187-249.

Arratia, G., and H.P. Schultze. 2013. Outstanding features of a new Late Jurassic pachycormiform fish from the Kimmeridgian of Brunn, Germany and comments on current understanding of pachycormiforms. In Mesozoic fishes 5-global diversity and evolution, eds. G. Arratia, H.P. Schultze, and M.V.H. Wilson, 87-120. München: F. Pfeil.

Bartsch, P. 1988. Funktionelle Morphologie und Evolution des Axialskelettes und der Caudalis ursprünglicher Knochenfische. Palaeontographica A 204: 117-226.

Berg, L.S. 1937. A classification of fish-like vertebrates. Bulletin de l'Académie des Sciences de l'URSS. Classe des Sciences mathématiques et naturelles (série biologique) 4: 1277-1280. (in English and Russian).

Berg, L.S. 1940. Classification of fishes both recent and fossil. Trudy Zoologicheskogo Instituta, Akademia Nauk S.S.S.R 5: 346-517.

Blainville, H.M.D. de. 1818. Poissons fossiles. Nouveau Dictionnaire d'Histoire Naturelle 27: 310-395.

Caine, H., and M.J. Benton. 2011. Ichthyosauria from the Upper Lias of Strawberry Bank, England. Palaeontology 54: 1069-1093.

Cope, E.D. 1887. Zittel's manual of palaeontology. American Naturalist 21: 1014-1019.

Delsate, D. 1999. Haasichthys michelsi, nov. gen., nov. sp., un nouveau Pachycormiforme (Osteichthyes, Actinopterygii) du Toarcien inférieur (Jurassique) luxembourgeois. Travaux Scientifiques du Musée National d'Histoire Naturelle du Luxembourg 32: 87-140.

Everhart, M.J. 2005. Oceans of Kansas. A natural history of the Western Interior Sea. Bloomington: Indiana University Press.

Friedman, M. 2012. Parallel evolutionary trajectories underlie the origin of giant suspension-feeding whales and bony fishes. Proceedings of the Royal Society London, Biological Sciences 279: 944-951.

Friedman, M., K. Shimada, L.D. Martin, M.J. Everhart, J. Liston, A. Maltese, and M. Triebold. 2010. 100-million-year dynasty of giant planktivorous bony fishes in the Mesozoic seas. Science 327: 990-993.

Gregory, W.K. 1933. Fish skulls. A study of the evolution of natural mechanisms. Transactions of the American Philosophical Society 23: $75-481$.

Gouiric-Cavalli, S., and A.L. Cione. 2015. Notodectes is the first endemic pachycormiform genus (Osteichthyes, Actinopterygii, Pachycormiformes) in the Southern Hemisphere. Journal of Vertebrate Paleontology 35 (4): e933738.

Hallam, A. 1967. An environmental study of the Upper Domerian and Lower Toarcian in Great Britain. Philosophical Transactions of the Royal Society of London. Series B, Biological sciences 252: 393-445.

Hudson, J.D., and D.M. Martill. 1994. The Peterborough Member (Callovian, Middle Jurassic) of the Oxford Clay Formation at Peterborough, UK. Journal of the Geological Society 151: 113-124.
Huxley, T.H. 1880. On the applications of the laws of evolution to the arrangement of the Vertebrata and more particularly of the Mammalia. Proceedings of the Zoological Society of London 43: 649-662.

Jollie, M. 1962. Chordate morphology. New York: Reinhold Publishing Corporation.

Kear, B.P. 2007. First record of a pachycormid fish (Actinopterygii: Pachycormiformes) from the Lower Cretaceous of Australia. Journal of Vertebrate Paleontology 27: 1033-1038.

Lambers, P. 1988. Orthocormus teyleri nov. spec., the first pachycormid (Pisces, Actinopterygii) from the Kimmeridge Lithographic Limestone at Cerin (Ain), France; with remarks on the genus Orthocormus Weitzel. Proceedings of the Koninklijke Nederlandse Akademie van Wetenschappen Series B 91: 369-391.

Lambers, P. 1992. On the ichthyofauna of the Solnhofen Lithographic Limestone (Upper Jurassic, Germany). Unpublished $\mathrm{PhD}$ thesis. Groningen: University of Groningen.

Lindkvist, M. 2012. A phylogenetic appraisal of pachycormus bollensis: implications for Pachycormiform evolution. Unpublished bachelors thesis. Uppsala: Uppsala University.

Liston, J. 2006. A fish fit for Ozymandias?: the ecology, growth and osteology of Leedsichthys (Pachycormidae, Actinopterygii) Unpublished PhD thesis. Glasgow: University of Glasgow.

Liston, J. 2013. The plasticity of gill raker characteristics in suspension feeders: implications for Pachycormiformes. In Mesozoic fishes 5-global diversity and evolution, eds. G. Arratia, H.P. Schultze, and M.V.H. Wilson, 121-143. München: F. Pfeil.

Liston, J., and A.E. Maltese. 2017. Hips, tips and sweet sweptback rays: Looking beyond traditional cranial characters in Pachycormiformes. PeerJ Preprints. https://doi.org/10.7287/peerj.prepr ints.3170v1.

Liston, J., M. Newbrey, T. Challands, and C. Adams. 2013. Growth, age and size of the Jurassic pachycormid Leedsichthys problematicus (Osteichthyes: Actinopterygii). In Mesozoic fishes 5-global diversity and evolution, eds. G. Arratia, H.P. Schultze, and M.V.H. Wilson, 145-175. München: F. Pfeil.

Mainwaring, A.J. 1978. Anatomical and systematic review of the Pachycormidae, a family of Mesozoic fossil fishes. Unpublished $\mathrm{PhD}$ thesis. London: Westfield College.

Maltese, A., and J.J. Liston. 2014. Daggers, swords, scythes and sickles: pachycormid fins as ecological predictors. PeerJ Prints. https ://doi.org/10.7287/peerj.preprints.2550v1.

Marek, R.D., B.C. Moon, M. Williams, and M.J. Benton. 2015. The skull and endocranium of a Lower Jurassic ichthyosaur based on digital reconstructions. Palaeontology 58: 732-745.

Massare, J.A. 1987. Morphology and prey preference of Mesozoic marine reptiles. Journal of Vertebrate Paleontology 7: 121-137.

Meunier, F.J., and P.M. Brito. 2004. Histology and morphology of the scales in some extinct and extant teleosts. Cybium 28 (3): 225-235.

Moore, C. 1864. On the geology of the South West of England. Monthly Journal of Geology 1: 235-236.

Patterson, C. 1973. Interrelationships of holosteans. In Interrelationships of fishes, eds. P.H. Greenwood, R.S. Miles, and C. Patterson, 233-305. London: Academic Press.

Patterson, C. 1975. The braincase of pholidophorid and leptolepid fishes, with a review of the actinopterygian braincase. Philosophical Transactions of the Royal Society of London (B) 269: 275-579.

Pierce, S.E., and M.J. Benton. 2006. Pelagosaurus typus Bronn, 1841 (Mesoeucrocodylia: Thalattosuchia) from the Upper Lias (Toarcian, Lower Jurassic) of Somerset, England. Journal of Vertebrate Paleontology 26: 621-635.

Regan, T. 1925. The skeleton of Lepisosteus, with remarks on the origin and evolution of the lower Neopterygian fishes. Proceedings of the Zoological Society of London 1923: 445-461. 
Schultze, H.P. 1966. Morphologische und histologische Untersuchungen an den Schuppen mesozoischer Actinopterygier (Übergang von Ganoid-zu Rundschuppen). Neues Jahrbuch für Geologie und Paläontologie, Abhandlungen 126: 232-314.

Schultze, H.P. 1993. The head skeleton of fishes. In The skull, vol. 2, eds. J. Hanken and B.K. Hall, 189-254. Chicago: The University of Chicago Press.

Schultze, H.P. 1996. The scales of Mesozoic actinopterygians. In Mesozoic fishes-systematics and paleoecology, eds. G. Arratia and G. Viohl, 83-93. München: F. Pfeil.

Schultze, H.P. 2008. Nomenclature and homologization of cranial bones in actinopterygians. In Mesozoic fishes 4-nomenclature and homology, eds. G. Arratia, H.P. Schultze, and M.V.H. Wilson, 23-48. München: F. Pfeil.

Schultze, H.P. 2016. Scales, enamel, cosmine, ganoine, and early osteichthyans. Comptes Rendus Palevol 15 (1-2): 83-102.

Schultze, H.P., and M. Arsenault. 1985. The panderichthyid fish Elpistostege: A close relative of tetrapods. Palaeontology 28: 293-309.

Sferco, E., A. López-Arbarello, and A.M. Báez. 2015. Phylogenetic relationships of $\dagger$ Luisiella feruglioi (Bordas) and the recognition of a new clade of freshwater teleosts from the Jurassic of
Gondwana. BMC Evolutionary Biology. https://doi.org/10.1186/ s12862-015-0551-6.

Wenz, S. 1967. Compléments à l'étude des poissons actinoptérygiens du Jurassique français. Cahiers de Paléontologie 1967: 1-276.

Westoll, T.S. 1943. The origin of the tetrapods. Biological Reviews 18 (2): 78-98.

Williams, M., M.J. Benton, and A. Ross. 2015. The Strawberry Bank Lagerstätte reveals insights into Early Jurassic life. Journal of the Geological Society 172: 683-692.

Woodward, A.S. 1890. On a head of Eurycormus from the Kimmeridge Clay of Ely. Geological Magazine (Decade III) 7: 288-293.

Woodward, A.S. 1895. Catalogue of the fossil fishes in the British Museum, vol. 3. London: British Museum of Natural History.

Woodward, A.S. 1896. On the fossil fishes of the Upper Lias of Whitby, Part II. Proceedings of the Yorkshire Geological and Polytechnic Society 3: 155-170.

Wretman, L., B. Henning, and B.P. Kear. 2016. Resolution of the Early Jurassic actinopterygian fish Pachycormus and a dispersal hypothesis for Pachycormiformes. Journal of Vertebrate Paleontology. https://doi.org/10.1080/02724634.2016.1206022. 